\title{
Comparison of ambulance usage characteristics in children between the pre-pandemic and pandemic periods in Turkey
}

\author{
Eyüp Sarı ${ }^{1}$, İshak Şan ${ }^{2}$, Burak Bekgöz ${ }^{2}$, and HALISE AKÇA ${ }^{3}$ \\ ${ }^{1}$ SBU Ankara Dr Sami Ulus Maternity Child Health and Diseases Training and Research \\ Hospital \\ ${ }^{2}$ Ministry of Health Ankara City Hospital \\ ${ }^{3}$ Ankara Yildirim Beyazit University Faculty of Medicine
}

May 14, 2021

\begin{abstract}
Aim: A pandemic is an epidemic of an infectious disease that has spread across a large region of the world and affects many people. In this study, it was aimed to evaluate the impact of the coronavirus disease 2019 (COVID-19) pandemic on ambulance use by pediatric patients in .............. Turkey. Materials and Methods: This retrospective study was conducted in the spring-summer of 2019 and 2020. The electronic medical records of pediatric patients who were transported to the hospital by ambulance were analyzed. Results: It was determined that $49.6 \%$ of the 23,201 patients included in the study were transported during the pandemic period. Male gender was higher in both the pandemic and pre-pandemic periods, there was no difference in terms of average age. The rate of forensic cases and refugee patients increased, while that of emergency patients decreased. Both the arrival at the scene time and intervention time were prolonged. Medical cause was the most common cause of emergency calls in both years, however, it increased significantly in 2020. The decrease in cases of traffic accidents, suicides, and other accidents was statistically significant. In the pandemic period, total rate of COVID-19 infection and suspicion was 29.7\%. Most of the patients had been referred to a public hospital. Conclusion: It was found that most of the ambulances were used for transporting patients with minor illnesses that did not require immediate medical attention.
\end{abstract}

\section{Hosted file}

Manuscript.pdf available at https://authorea.com/users/413778/articles/521979-comparisonof-ambulance-usage-characteristics-in-children-between-the-pre-pandemic-and-pandemicperiods-in-turkey

\section{Hosted file}

Table 1.pdf available at https://authorea.com/users/413778/articles/521979-comparisonof-ambulance-usage-characteristics-in-children-between-the-pre-pandemic-and-pandemicperiods-in-turkey

\section{Hosted file}

Table 2.pdf available at https://authorea.com/users/413778/articles/521979-comparisonof-ambulance-usage-characteristics-in-children-between-the-pre-pandemic-and-pandemicperiods-in-turkey

\section{Hosted file}


Table 3.pdf available at https://authorea.com/users/413778/articles/521979-comparisonof-ambulance-usage-characteristics-in-children-between-the-pre-pandemic-and-pandemicperiods-in-turkey

\section{Hosted file}

Table 4.pdf available at https://authorea.com/users/413778/articles/521979-comparisonof-ambulance-usage-characteristics-in-children-between-the-pre-pandemic-and-pandemicperiods-in-turkey 